IZA DP No. 6198

Scarring Effects of Unemployment

Øivind A. Nilsen

Katrine Holm Reiso

December 2011

Forschungsinstitut zur Zukunft der Arbeit Institute for the Study of Labor 


\title{
Scarring Effects of Unemployment
}

\author{
Øivind A. Nilsen \\ Norwegian School of Economics \\ and IZA \\ Katrine Holm Reiso \\ Norwegian School of Economics
}

Discussion Paper No. 6198

December 2011

\author{
IZA \\ P.O. Box 7240 \\ 53072 Bonn \\ Germany \\ Phone: +49-228-3894-0 \\ Fax: +49-228-3894-180 \\ E-mail: iza@iza.org
}

\begin{abstract}
Any opinions expressed here are those of the author(s) and not those of IZA. Research published in this series may include views on policy, but the institute itself takes no institutional policy positions.

The Institute for the Study of Labor (IZA) in Bonn is a local and virtual international research center and a place of communication between science, politics and business. IZA is an independent nonprofit organization supported by Deutsche Post Foundation. The center is associated with the University of Bonn and offers a stimulating research environment through its international network, workshops and conferences, data service, project support, research visits and doctoral program. IZA engages in (i) original and internationally competitive research in all fields of labor economics, (ii) development of policy concepts, and (iii) dissemination of research results and concepts to the interested public.
\end{abstract}

IZA Discussion Papers often represent preliminary work and are circulated to encourage discussion. Citation of such a paper should account for its provisional character. A revised version may be available directly from the author. 


\section{ABSTRACT}

\section{Scarring Effects of Unemployment ${ }^{*}$}

Using Norwegian individual register data of young workers, from the period 1986-2008, we analyse whether there are large and persistent negative relationships between unemployment and the risk of repeated unemployment and being out of labour force. A nearest-neighbour propensity score matching method is applied to make the treatment group (the unemployed) and the control group (the employed) as similar as possible. By tracking workers over a 10-year follow-up period, we find that unemployment has a negative effect on later labour market attachment. This is consistent with existing findings in the literature. The negative effects decrease over time. Using the bounding approach proposed by Rosenbaum (2002) to analyse the importance of unobserved variables, our results indicate that a relatively high level of unobserved selection bias could be present in the data before changing the inference. Thus, unemployment leaves young workers with long-term scars.

JEL Classification: J64, J65, C23

Keywords: $\quad$ unemployment persistency, scarring, matching technique

Corresponding author:

Katrine Holm Reiso

Norwegian School of Economics

Department of Economics

Hellevn. 30

5045 Bergen

Norway

E-mail: katrine.reiso@nhh.no

\footnotetext{
"We appreciate comments during presentation at the "Annual Meeting for Norwegian Economists" 2011, Nordic Econometric Meeting 2011, Statistics Norway, ESEM 2011, Norwegian School of Economics, EALE 2011, $7^{\text {th }}$ Norwegian-German CESifo Seminar and fruitful discussions with Rolf Aaberge, Astrid Kunze, and Kjell Salvanes.
} 


\section{Introduction}

"Scarring" is defined as the negative long-term effect that unemployment has on future labour market possibilities in itself. Thus, an individual who has been unemployed will be more likely to suffer from negative labour market experiences in the future, compared to an otherwise identical individual who has not been unemployed. In the short-term, an unemployment period will imply a direct income loss. There are several studies, however, indicating that an unemployment period deteriorates future labour market possibilities and thus has severe long-term consequences as well. Arulampalam et al. (2000) and Gregg (2001) show evidence of state dependence scarring effects in individual unemployment histories (see also Biewen and Steffens (2010) for a German study). Norwegian papers of particular interest are Raaum and Røed (2006) that find patterns of youth unemployment persistence, and studies of downsizing (Huttunen et al., 2011, Bratsberg et al., 2010) which find increased probabilities of leaving the labour force for displaced workers. Bratsberg et al. (2010) show that 28 percent of all new disability insurance claims among males in Norway can be attributed to job displacement, implying that unemployment may be a pathway to disability pension. Thus, the direct costs associated with an unemployment period, for both the society and the individual, may be only the tip of an iceberg. Summarising the quite extensive literature on scarring, there seems to be ample evidence of state dependency in unemployment histories.

While there is evidence of a true scarring effect in the existing literature, less is known about its cause. Possible explanations are depreciation of human capital (Becker, 1993), psychological discouragement or habituation effects (Clark et al., 2001), theories of job matching where the unemployed accept poorer quality jobs (Pissarides, 1994), social work norms that influence individuals preferences for work (Stutzer and Lalive, 2004), and 
employers using individual's unemployment as a signal of low productivity (Lockwood, 1991). In the latter case, individuals with a history of unemployment may face systematically lower chances of finding employment, even though they are identical to the other job seekers with regards to other characteristics that are observable to the employer.

When it comes to unemployment, it is well known that younger workers are affected more severely than their older and more established counterparts. This has become particularly evident during the current financial crisis and recessionary conditions afflicting several countries, especially those in the southern parts of Europe. Furthermore, one might think that the scarring effects are more significant for younger workers without a long employment history. Indeed, this seems to be the general belief among policy-makers, who often make specific active labour market programs targeting young workers. In other words, having unemployment spells might be considered a stronger signal about the qualifications and skills of young workers, rather than older ones. In addition, if a period of unemployment causes permanent exits form the labour market this may be particularly severe for the young who have their entire working career a head of them as opposed to the older workers who are closer to their retiring age. Thus, it seems reasonable to focus on relatively young workers when analysing the consequences of unemployment.

The aim of this paper is to analyse the magnitude of possible scarring effects of unemployment on future labour market status, being unemployed and being out of labour force, among young Norwegian workers. ${ }^{1}$ We therefore focus on young individuals who already have some work experience. ${ }^{2}$ Following a standard practice in labour market studies,

\footnotetext{
${ }^{1}$ We do not focus on wage scarring for those who return to employment. While there is evidence of wage scarring in the literature, this seems to be of less concern in a Norwegian context. Huttunen et al. (2011) find moderate effects of displacement on earnings for those who remain in the labour force, while the effects of displacement on the probability of leaving the labour force are large.

${ }^{2}$ There is of course an extensive literature on the school-to-work transition. However, since we focus on young workers with at least two years of continuous experience, we do not discuss this literature.
} 
we analyse the potential scarring effects separately for males and females. Reasons for such potential gender differences are for instance educational differences, occupational choice, family patterns and preferences. There are several reasons to focus on the Norwegian labour market. First, Norway has traditionally had a very low unemployment rate. For this reason, one might think that the scarring effects should be high, since being one out of few unemployed individuals may be perceived as a stronger signal of the individual's abilities by the employer than being one out of many unemployed when unemployment is high. Second, Norway is considered to be a well-developed welfare state. This might lead to longer unemployment and negative selection into disability pension. With free education, a failure of an individual's success in the labour market might therefore only reflect ones observed and unobserved lack of skills, or match made in the labour market. Thus, getting a diagnosis that gives one the option of stepping out of the labour force due to disability might be tempting. On the other hand, the authorities may also put significant effort into ensuring that everybody has a relatively good attachment to the labour market.

The data employed in this study have several advantages. First, they provide us with a very long time series. Second, the data sources are administrative registers, e.g. the public tax register, thereby reducing the problems of self-reporting errors, attrition, etc. Third, they are census data and therefore highly representative and provide a large number of observations. Finally, unlike most other studies in this field, they include information about females.

The focus is on young individuals (i.e. those who completed their education at most ten years prior to a potential unemployment experience), which registered as unemployed during the years 1990-1998. A comparison group is formed, constituted by young individuals who are employed. The labour market status of the two groups is recorded in the ten subsequent years. To make the two groups as comparable as possible, we use a nearest 
neighbour propensity matching estimator. We also address the role of unobserved variables by using the approach proposed by Rosenbaum (2002). Our main finding is that there exists a large and persistent negative relationship between previous unemployment and future labour market status of being unemployed and being out of labour force. This indicates that there may be a considerable scarring effect of unemployment. The estimated relationships are similar for females and males.

The structure of the paper is as follows. Section 2 presents some information about intuitional settings in Norway. Section 3 presents the data, while a description of the matching procedure is provided in Section 4. Section 5 presents the results and this is followed by some sensitivity analyses in Section 6. Finally, we offer some concluding remarks in Section 7.

\section{Institutional Settings}

The unemployment rate in Norway has traditionally been very low. Still, we note that unemployment among the younger cohorts is much higher than for older individuals. For instance, in 1993, a recessionary year in Norway, the unemployment rate among males aged 15-24 years was 14.4 , while it was only 5.7 among males aged 25-54. The corresponding numbers for females were 12.9 and 4.2, respectively. In 1998, a booming year in the Norwegian economy, the corresponding numbers were 9.1 and 2.2 for men, and 9.5 and 2.3 for females, respectively. ${ }^{3}$ The gender difference in unemployment rates among younger individuals may be a result of the fact that males are traditionally employed in sectors that are more exposed to business cycle fluctuations (for instance manufacturing and construction), while females are more typically employed in the public sector. It should also be mentioned that the gender segregation in the Norwegian labour market is quite high (see OECD 2002).

\footnotetext{
${ }^{3}$ Source: Statistics Norway
} 
Moreover, females have more education than males among the youngest cohorts. For instance, based on numbers for individuals aged 25-29 in 1999, 30.6 percent of males have a university education, while the corresponding number for females is $39.2 .^{4}$

Individuals who are either residents or work as employees in Norway are automatically insured under the National Insurance Scheme. The conditions for receiving unemployment benefits are that the worker has previously earned income, has lost his job for reasons beyond his control, and is actively seeking employment and capable of work. ${ }^{5}$ To receive state benefits during the review period of this study, 1990-1998, a beneficiary needed to earn a minimum of approximately 50000 NOK (2009) the year prior to becoming unemployed, or twice this amount during the last three years prior to unemployment (NAV, 2010). ${ }^{6}$ The benefit received is 62.4 percent of previous earnings up to a certain maximum amount. $^{7}$ The unemployment benefit period varies depending on previous earnings; benefits could in practice be received for about three years in the period 1990-1998. ${ }^{8}$

The two main laws regulating hires and fires in Norway are the law of employment ("Sysselsettingsloven”), and the law of labour relations (“Arbeidsmiljøloven"). Still, there is no legal rule on the selection of workers to be dismissed in case of mass lay-off. In the main collective agreement ("Hovedavtalen") between the labour unions and the employers association (NHO) it is stated that employers should emphasise seniority when restructuring and during mass-lay-offs. However, it is possible to ignore the seniority rule if there are good reasons for this.

\footnotetext{
${ }^{4}$ Source: Statistics Norway

${ }^{5}$ However, individuals who quit voluntarily, or are dismissed due to reasons within their control, may also receive benefits after a certain waiting period of at least eight weeks.

${ }^{6} 1 \mathrm{NOK} \approx 1 / 8$ Euro.

${ }^{7}$ The maximum amount is approx. 270000 NOK in 1998.

${ }^{8}$ It is also possible to continue receiving unemployment benefits after an interruption within 52 weeks without having to meet the minimum earnings threshold.
} 


\section{Data}

\subsection{Sample constructing}

The data are drawn from data produced by Statistics Norway and include information on all Norwegian residents between 16 and 74 years of age. This includes employment relationships, labour market status, earnings, education, age, experience, material status and municipality of residence, collected from different administrative registers for the years 1986 to 2008. They are census data, making them highly representative and provide a large number of observations. There is also information about the number of months an individual has been registered as unemployed during a year. Both individuals who are entitled to unemployment benefits, and individuals who are not, may register as unemployed. An initiated month of registered unemployment is categorized as an entire month even if the unemployment spell is shorter. Data from the Norwegian Social Science Data Services are used to construct unemployment rates separately for males and females for 46 regional labour markets in the years $1990-1998 .^{9}$

The sample is constructed by pooling all individuals in the period 1990 to 1998 , which constitute the base years. ${ }^{10}$ In a base year only individuals in the labour force are included. On the basis of their employment status, they are divided into two groups: employed and unemployed. Every individual that is registered with a plant identification number, i.e. has an employer in the register-months, being May in the years 1990-1995, and November in the years 1996-1998, and is not registered with any months of unemployment and is not a

\footnotetext{
${ }^{9}$ The 46 regional labour markets are categorized by Statistics Norway and classified according to commuting statistics (Bhuller, 2009).

${ }^{10}$ These exact base years are chosen so that it is possible to observe the individuals' registered unemployment histories two years prior to a base year, for reasons to be explained, and to follow individuals up to ten years after a base year. The registered unemployment variable is only available from 1988
} 
fulltime student (i.e. not registered with on-going education and working less than 20 hours a week) in a given base year is part of the employed group. ${ }^{11,12}$ All individuals with registered unemployment, regardless of whether they are fulltime students or have a plant identification number or not, are part of the unemployed group. Individuals in a base year that are neither part of the employed group nor part of the unemployed group are excluded. ${ }^{13}$

We want the sample to consist of individuals who are entitled to unemployment benefits in a base year so that it is economically beneficial for the individuals who lose their job in that year to register as unemployed rather than leaving the labour force. Hence, we restrict the sample to regular workers with a minimum of two years of work experience prior to a base year. Thus, only individuals who have been working at least 20 hours a week at a plant and are classified as receiving wage in the tax-records in the two years prior to a base year are included. Individuals with on-going education or completed education the two most recent years prior to a base year are excluded. Furthermore, all individuals with registered unemployment in the two years prior to a base year are excluded. The latter both increases the probability that the remaining individuals are actually regular workers, and ensures that all registered unemployed in a base year have started their unemployment period in that respective base year. Also individuals not working in Norway in the two years prior to a base year are excluded.

Since we are interested in scarring early in the career, we limit our sample to individuals who have ended their education within 3-10 years prior to a base year. We

\footnotetext{
${ }^{11}$ In addition, individuals not registered with a plant identification number and not registered with any months of unemployment in a year are categorized as being employed in that respective year if they satisfy the following criterion; they are registered with an identical plant identification number the year prior and subsequent to the year the plant identification number is missing.

${ }^{12}$ Note that this definition of employment also includes part time workers.

${ }^{13}$ Note that even though there are 9 base years in total, there is only one base year observation per individual. For individuals who satisfy the criteria of being in the sample multiple base years, the earliest base year observation is used.
} 
condition on years since ended education and not age per se so that the higher and lower educated have a similar amount of labour market experience. Individuals who have not finished their education within a time frame of two years prior and five years after what is expected had they taken their education non-stop from they started primary school, are excluded. ${ }^{14}$ These latter restrictions, combined with the minimum of two years of work, make the unemployed and the employed groups similar in terms of labour market experience. In addition, individuals with less than 9 years of education in a base year are excluded.

The employment statuses for the two comparison groups - i.e. those who were employed in a base year versus those who were unemployed - are compared yearly for a period of 10 years following a base year, referred to as the follow-up years. For each of the follow-up years the individuals' employment statuses are divided into three categories: employed, unemployed and not participating in the labour force, i.e. out of labour force. To be classified as employed or unemployed the same criteria applies as for the classification of these two groups in a base year. Individuals with missing information on a multiple of accessible employment relationship variables and not already classified as employed or unemployed are classified as out of labour force. ${ }^{15}$ Also individuals who are fulltime students, i.e. registered with on-going education and working less than 20 hours a week, are classified as out of labour force. ${ }^{16}$ Individuals with uncertain employment status in the follow-up years, not corresponding to any of the above employment status categories are excluded $(8.5 \%$ of sample). In addition, individuals with incomplete relevant data are also excluded.

\footnotetext{
${ }^{14}$ In the years following a base year the individuals have the option of taking further education. This option is not restricted since taking more education may be a consequence of experiencing unemployment in a base year.

15 The employment relationship variables include plant identification number, firm identification number, municipality of work and start and termination date of employment relationships.

${ }^{16}$ For the years 2007 and 2008 the variable with information about ongoing education is not available. In these years students who work, even if it is less than 20 hours a week, are categorized as employed if they have no months of registered unemployment. We tend to believe that this affects only very few individuals.
} 
The data contains both personal and demographic characteristics of the individuals, including age, years of education, earnings (fixed NOK 2000 prices), marital status and whether the individual is born outside of Scandinavia. We also have information on type of education, industry and region of residence. For the analysis, both education type and industry type are divided into 9 categories. ${ }^{17}$ Region of residence is divided into 7 major areas defined by Statistics Norway (Hartvedt et al., 1999), ranging from the urban capital region to the relatively rural micro regions. In addition we have regional labour market unemployment rates constructed by gender.

\subsection{Descriptive analysis}

[Table 1 "Descriptive statistics before matching" about here]

Table 1 reports characteristics of the two groups being employed and unemployed in a base year by gender. All characteristics are measured in the year prior to the base year. Even though the employed and unemployed groups are relatively similar, they are not identical. Individuals in the unemployed group are younger, less likely to be married (especially males), and have lower levels of education and lower wages. They are more likely to be nonScandinavian. Among other things, they are also less likely to work in the public sector, more likely to be in the construction industry, and less likely to live in the capital region. Moreover, individuals in the unemployed group typically live in local labour market areas with higher unemployment rates in a base year.

\footnotetext{
${ }^{17}$ See Statistics Norway (1989) for the educational type classification, and Statistics Norway (1983) for industry classification.
} 
The shares of individuals being unemployed and out of labour force in the follow-up years are shown in Figure A1 (males) and A2 (females) in the appendix, where we have split the sample according to their employment status in the base year, i.e. employed or unemployed. Since the two groups are not identical in terms of observed characteristics, these comparisons of their labour market statuses in the follow-up years may not be credible measures of the effect of unemployment per se. To construct a valid control group for the unemployed group we make use of matching. Without this matching, the differences between the employed group and the unemployed group in the follow-up years, may caused by differences in observed characteristics, and NOT due to the potential unemployment experience.

\section{Empirical Method}

\subsection{Matching estimator}

A standard model used to motivate matching is the potential outcome model or Rubin model (see Holland 1986, and Caleido and Kopening 2008). In this model there is a treatment indicator $D_{i}$, which as a binary variable takes the value 1 if individual $i$ receives treatment and 0 otherwise. The individual has two potential outcomes; $Y_{i}^{1}$ denotes the outcome if treated and $Y_{i}^{0}$ denotes the outcome if untreated. In regard to this analysis the treatment $D_{i}$ indicates whether the individual is in the unemployed group, i.e. has experienced unemployment in a base year, or not. Since we are interested in the effect of unemployment on future labour market statuses it would be desirable to compare the potential outcomes $Y_{i}^{l}$ (labour market status if experienced unemployment) and $Y_{i}^{0}$ (labour market status if not experienced unemployment) for individuals in the unemployed group. However, one can only observe a single outcome for each individual in the unemployed group, $Y_{i}^{l}$, and not the potential 
outcome for these same individuals had they not been unemployed, $Y_{i}^{0}$. Hence, one can only compare mean differences in outcomes in the population and get average treatment effects.

Thus, what we are interested in is the average treatment effect on the treated (ATT), defined as:

$$
\tau^{A T T}=E\left(Y^{1} \mid D=1\right)-E\left(Y^{0} \mid D=1\right)
$$

Notice that also $E\left(Y^{0} \mid D=1\right)$ is never observed. Using the mean outcome of the employed group $E\left(Y^{0} \mid D=0\right)$ may not be a proper substitute for $E\left(Y^{0} \mid D=1\right)$. This is because characteristics which determine whether an individual became unemployed in a base year are likely also to determine the individual's future labour market status. In other words, there might be a selection into unemployment. The average treatment effect on the treated is estimated using a matching method. In essence, this method makes sure that a comparable employed group is equal to the unemployed group in terms of observed characteristics.

For identification in this model, it is assumed that the unemployed and the employed group are different because they differ with regard to observed characteristics only. This is to say that given the observed characteristics, $X$, the potential outcomes are independent of treatment, i.e. the unemployment incidence in a base year. Formally: $Y^{0}, Y^{1} \| D \mid X$, where $\|$ denotes independence. This is called the Conditional Independence Assumption (CIA). CIA is a strong assumption and requires no selection on unobserved characteristics. However, since we can never be certain about whether there actually is selection on unobservable characteristics, we test the sensitivity of our results to different levels of unobserved heterogeneity causing selection into unemployment as a robustness check in section 6 . 
Another requirement for matching is the common support condition. This condition ensures that there exists a counterpart for every individual in the unemployed group. This restriction is of less concern in this case since we have an employment group that is much larger than the unemployed group. For males, there are a total of 196702 individuals in the employed group and 17169 individuals in the unemployed group. For females, the breakdown is 159398 in the employed group and 12187 in the unemployed group, respectively.

We match the individuals using propensity scores. This is a simple method that diminishes the dimensionality problem when having many and continuous observed variables. The propensity score is defined as $p_{i}\left(x_{i}\right)=\operatorname{Pr}\left(D_{i}=1 \mid x_{i}\right)$, where $x_{i}$ is the vector of observed characteristics for individual $i$. Thus, the propensity score gives each individual a probability of experiencing unemployment. Rosenbaum and Rubin (1983) showed that conditioning on $p(x)$ instead of $X$ is sufficient to identify the treatment effect, given that CIA and the common support condition holds. With respect to the propensity score, individuals in the unemployed group are matched to the nearest individual in the employed group without replacement.

\subsection{Common support and matching quality}

The propensity scores are estimated separately for males and females using logistic regressions. The dependent binary variable takes the value 1 if an individual is unemployed in a base year and zero otherwise. All controls from the summary statistics reported in Table 1, measured the year prior to a base year, are included in the estimations. In addition to base year dummies, the square root of age, and regional labour market unemployment rates measured in the base years. 
Without going into details, it could be mentioned that for males the coefficients of the base year dummies from the logistic regression follow the pattern of the overall unemployment rates for the years 1990-1998, with a peak in the likelihood of unemployment in early nineties, and a slump in 1997-1998. ${ }^{18}$ We also find the local unemployment rates positive and highly significant. Furthermore, education, income, age - which might also proxy experience, and marriage increase the probability of staying employed. The results for females are much the same as for males, except that the coefficients for the base year dummies seem to be rather flat. This difference is consistent though, with the gendersegregated labour market in Norway, as described in Section 2, with females being overrepresented in the public sector and not exposed to business cycles to the same degree as men.

[Figure 1 "Propensity scores - males" about here]

[Figure 2 "Propensity scores - females" about here]

To evaluate whether the common support condition is satisfied we investigate the distributions of the estimated propensity scores. Figures 1 and 2 show the distribution of the estimated propensity scores before and after matching for males and females, respectively, in both the treatment (i.e. unemployed) and control (i.e. employed) groups. While the distributions for the treatment and control groups differ, the distribution of the control group covers the range of the treatment group. In addition, the extreme values (minimum and maximum) of the propensity scores for the treated group are within the extreme values of the

\footnotetext{
${ }^{18}$ These results are not reported but available from the authors on request.
} 
control group. This indicates that the common support condition is satisfied. After matching, the distributions of the two groups are visually identical for both genders.

[Table 2 "Descriptive statistics after matching" about here]

The quality of the propensity score matching is evaluated by doing a visual inspection of the means of the observed characteristics for the treatment and the control group after matching, and calculating absolute standardised biases (Rosenbaum and Rubin 1985) and $t$-tests. Examination of the results in Table 2 shows that the observed characteristics are extremely similar after matching. There is no bias larger than $2 \%$ for any of the observed characteristics for neither males nor females. For most of the observed characteristic the bias is well below $2 \%$. In addition the $p$-values of the $t$-tests show that none of the means are significantly different in the two groups. Hence the matching procedure has generated a control group for the unemployed group that is, on average, identical.

\section{Results}

Since the matching method has removed most of the bias attributable to observed characteristics, an estimate of the average treatment effect on the treated groups is simply found by taking the difference in mean outcomes in the unemployed group and the matched control group. The effects of experiencing unemployment are shown in Figures 3-6. The probability differences for the treated group (i.e. those who experience unemployment) and the control group on later unemployment and of being out of labour force for males are reported in Figures 3 and 4 respectively. 
[Figure 3 “ATT - unemployment for males" about here]

Starting with the average treatment effects on the treated on unemployment, reported in Figure 3, we see that this is 40 percentage points the first follow-up year. Note, however, that in the first follow-up year it is likely that many individuals in the unemployed group are in the same continuous unemployment spell that started in a base year. The estimated effect drops to about 10 percentage points in the fifth year. Looking at the probabilities behind this figure in follow-up year five, we find that those in the control group have a probability of 7.8 percent of being unemployed, while the corresponding number for the unemployed individuals is much higher at 17.2 percent. Turning to the evolution over time, we see that the average treatment effects seem to stabilize at five percentage points from year eight onwards. With regards to the latter stabilization, the underlying reason is that the ones in the treatment group have a probability of unemployment of 11 percent, while the control group have a probability of 6 percent.

[Figure 4 “ATT - out of labour force for males" about here]

Moving now to the treatment effects on being out of labour force, this seems quite stable over time. It appears to be consistent with the findings reported in Huttunen et al. (2011) (see their Figure 3), where they analyse the effects of job displacement in Norway, as well as Eliason and Storrie (2006) for Sweden, and Verho (2008) for Finland. Thus, there are large and persistent negative relationships between previous unemployment and future labour market status of being unemployed and being out of labour force for males. 
[Figure 5 “ATT - unemployment for females" about here]

[Figure 6 "ATT - out of labour force for females" about here]

The comparable figures for females are reported in Figures 5 and 6, which correspond to the difference in incidences of unemployment, and being out of labour force, respectively. Somewhat surprisingly, we find the pattern for females to be very similar to men; our prior beliefs were that we would find significant differences. As explained in Section 2, females seem to undertake more education, typically work in different industries and tend to be more family-oriented earlier in the life-cycle, when compared to men.

\section{Sensitivity analyses}

The results in Section 5 are based on the assumption that the CIA condition holds. If there are unobserved factors that differ across the treatment and the control groups that affect both the probability of becoming unemployed and the outcome variables being employed or out of labour force in the follow-up years, these results are not reliable causal effects of unemployment. It is imaginable that even though we have controlled for a variety of observed characteristics, there might be unobserved factors like productivity, preferences for work and ability causing selection bias. Since it is not possible to know whether there actually is important unobserved variables causing selection bias or not, we address this issue by calculating upper and lower bounds for the test statistic for different levels of unobserved heterogeneity, an approach proposed by Rosenbaum (2002). This allows us to test for how much unobserved heterogeneity must influence the selection process into unemployment before the estimated effects are no longer significant. 
The procedure outlined follows Aakvik (2001). The probability of being treated, i.e. being in the unemployed group for individual $i$ may be expressed as:

$$
\pi_{i}=\operatorname{Pr}\left(D_{i}=1 \mid x_{i}\right)=F\left(\beta x_{i}+\gamma u_{i}\right)
$$

where $u_{i}$ is an unobserved variable and $\gamma$ is the effect of $u_{\mathrm{i}}$ on the probability being in the unemployed group. If we let $F($.$) be the logistic distribution and assuming that we have a$ matched pair of individuals, $i$ and $j$, then the odds ratio (i.e. the relative odds of receiving treatment for these two individuals) may be written as:

$$
\frac{\frac{\pi_{i}}{1-\pi_{i}}}{\frac{\pi_{j}}{1-\pi_{j}}}=\frac{\pi_{i}\left(1-\pi_{j}\right)}{\pi_{j}\left(1-\pi_{i}\right)}=\frac{\exp \left(\beta x_{i}+\gamma u_{i}\right)}{\exp \left(\beta x_{j}+\gamma u_{j}\right)}=\exp \left[\gamma\left(u_{i}-u_{j}\right)\right]
$$

The $x$ vector cancels out since the two matched individuals have the same observed characteristics. If $e^{\gamma}=1$ then the two individuals have the same probability of being in the unemployed group. On the other hand, if $e^{\gamma}>1$ then the two matched individuals differ in their odds of being in the unemployed group. If a value of $e^{\gamma}$ slightly larger than 1 changes the inference about the effects of unemployment, the estimated effects are interpreted as being sensitive to unobserved selection bias. In contrast, if a large value of $e^{\gamma}$ does not change the inference, then we might say that the estimated effects are not sensitive to unobserved selection bias. A value of $e^{\gamma}=2$ changes the individuals relative differences of receiving treatment by a factor of 2, i.e. 100 percent. In line with the notions of Aakvik (2001), we also consider $e^{\gamma}=2$ to be a very large number. 
With fixed $e^{\gamma} \geq 1$ and binary $u$, the non-parametric Mantel-Haenszel (1959) teststatistics can be bounded by two known distributions (Rosenbaum (2002)). If $e^{\gamma}=1$ the bounds do not move apart and constitute the reference point of no unobserved selection bias. With $e^{\gamma}>1$ the bounds move apart showing the sensitivity of the test statistics to the presence of unobserved selection bias. There are two bounds: One is the test statistic when the effects of unemployment are overestimated, denoted $Q_{M H}^{+}$, and the other is the test statistic when the effects of unemployment are underestimated, denoted $Q_{M H}^{-}$. In Table 3 we report only the $p$ values of these test statistics. ${ }^{19}$

[Table 3 “Robustness check, MH-test" about here]

The Table 3 reports the $p$-values for both the upper and lower HM bounds for various values of $e^{\gamma}$; i.e. $e^{\gamma}=1$ (the reference point of no unobserved selection bias), $e^{\gamma}=1.5$, and $e^{\gamma}=$ 2. It does so for both the estimated effect of prior unemployment on unemployment and on out of labour force in each follow-up year. Starting with the robustness of unemployment for males, it turns out that all but a small minority of $p$-values are 0.00 . In other words, the estimated effects are not sensitive to unobserved selection bias. However, we do see that the estimated effects for out of labour force are somewhat more sensitive especially for the later follow-up years. This is likely to be caused by the fact that the estimates for average treatment effects are smaller when it comes to being out of labour force. Turning to females, the overall finding is consistent with the reported results for males with regards to unemployment. The test results for out of labour force are admittedly more sensitive to unobserved selection bias.

\footnotetext{
${ }^{19}$ In addition to Rosenbaum (2002) and Aakvik (2001), Caleido and Kopening (2008) give a practical overview of this approach.
} 
Note, however, that this does not mean that selection biases are present and we cannot say anything about the most likely magnitudes.

\section{Concluding remarks}

This paper contributes to the existing literature by investigating a possible scarring effect of unemployment on future labour market status for young workers with some years of work experience. The analysis is made separately for males and females. Taking advantage of rich and detailed register data from Norway, we use a matching estimator to construct a control group that is as similar as possible with regards to observables as to the individuals who experience an incidence of unemployment. This is done in an attempt to disentangle the effects of observables and the scarring effects.

The main finding is that there exists a large and persistent negative relationship between previous unemployment and future labour market status for both genders. For males, the average treatment effects on the treated on unemployment starts at 40 percentage points the first follow-up year, drops to 10 percentage points in the fifth year, and stabilizes around 5 percentage points from follow-up year 8 and onwards. The treatment effects on being out of labour force are about 4 percentage points and stable over time. Comparing males and females, we find the patterns to be very similar. When we analyze the sensitivity of the results using the Rosenbaum (2002) bounding approach, our results indicate that only a relatively high level of unobserved selection bias could change the inference. Thus, unemployment leaves young workers with long-term scars. These findings are consistent with findings from other Scandinavian studies of displacement, even though these studies are based on older and more established workers. Furthermore, the results of our analysis are for individuals with at least two years of labour market experience prior to their unemployment incidence. The 
unemployed with no prior work experience may be even more scarred. Thus, when we have ample evidence that the early labour markets history turns out to be decisive for subsequent labour market success, these findings may be used as support for significant public expenditures targeting young individuals. 


\section{References}

Aakvik, A. 2001. Bounding a matching estimator: the case of a Norwegian training program Oxford Bulletin of Economics and Statistics, 63(1), pp. 115-143, 2001.

Arulampalam, W., Booth, A.L., Taylor, M.P., 2000. Unemployment persistence. Oxford Economic Papers 52, 24-50.

Becker, G.S., 1993. Human Capital: A Theoretical and Empirical Analysis with Special Reference to Education. $3^{\text {rd }}$ Edition. NBER with The University of Chicago Press, Chicago, p. 29-58.

Bhuller, M.S., 2009. Inndeling av Norge i arbeidsmarkedsregioner. Statistisk Sentralbyrå (SSB). Notater 2009:24.

Biewen, M., Steffes, S., 2010. Unemployment persistence: Is there evidence for stigma effects? Economic Letters 106, 188-190.

Bratsberg, B., Fevang, E., Røed, K., 2010. Disability in the Welfare State: An Unemployment Problem in Disguise. IZA, Discussion Paper No. 4897.

Caleido, M., and S. Kopeinig 2008. Some Practical Guidance for the Implementation of Propensity Score Matching (2008), Journal of Economic Surveys, 22(1), 31-72.

Clark, A.E., Georgellis, Y., Sanfey, P., 2001. Scarring: The psychological impact of past unemployment. Economica, New Series, 68 (270), 221-241.

Eliason, M., and D. Storrie, 2006. Lasting or Latent Scars? Swedish Evidence on the LongTerm Effects of Job Displacement, Journal of Labor Economics 24(4), 831-856.

Gregg, P.,2001. The impact of youth unemployment on adult unemployment in the NCDS. Economic Journal 111(475), 626-653.

Hartvedt, H., Hustoft, A.G., Nymoen, E., Stålnacke, M., Utne, H., 1999. Standard for $\varnothing$ konomiske regioner. Statistics Norway (SSB), Oslo. Reports 99/6.

Holland, P. W. 1986. Statisticcs and Causal Inferencse, Journal of the American Statistical Association 81. 945-960.

Huttunen, K., Møen, J., Salvanes, K.G., 2011. How destructive is creative destruction? Effects of job loss on mobility, withdrawal and income. Journal of the European Economic Association 9(5), 840-870.

Lockwood, B., 1991. Information externalities in the labour market and the duration of unemployment. Review of Economic Studies 58 (4), 733-753. 
Mantel, N., and W. Haenszel, 1959. Statisctical Aspect of the Anaylisis of Data from Restrospective Studies of Disease, Journal of the National Cancer Institute 22(4), 719747.

Norwegian Labour and Welfare Administration (NAV), 2010. Grunnbeløpet (G).

OECD Employment Outlook, 2002. (chapter 2; Females at work: who are they and how are they faring?), 61-125.

Pissarides, A., 1994. Search unemployment with on-the-job search. Review of Economic Studies 61 (3), 457-475.

Raaum, O., Røed, K., 2006. Do business cycle conditions at the time of labor market entry affect future employment possibilities? Review of Economics and Statistics 88 (2), 193 210.

Rosenbaum, P. R 2002. Observational Studies. Springer New York.

Rosenbaum, P. R., and Rubin D. B., 1983. The central role of propensity score in observational studies of causal effects. Biometrika 70(1), 41-55.

Rosenbaum, P. R., and Rubin D. B., 1985. Constructing a control group using multivariate matched sampling methods that incorporate the propensity score. The American Statistician 39(1), 33-38.

SSB Statistics Norway, 1983. Standard industrial classification. Statistics Norway, OsloKongsvinger.

SSB Statistics Norway, 1989. Norwegian standard classification of education. Statistics Norway, Oslo-Kongsvinger.

Stutzer, A., Lalive, R., 2004. The role of social norms in job searching and subjective well-being. Journal of the European Economic Association 2 (4), 696-719.

Verho, J. 2008. Scars of recession: the long-term costs of the Finnish economic crisis, IFAU (Institute for Labour Market Policy Evaluation) WP 9. 
Table 1: Descriptive statistics before matching

Mean values and shares. All characteristics measured the year prior to a base year.

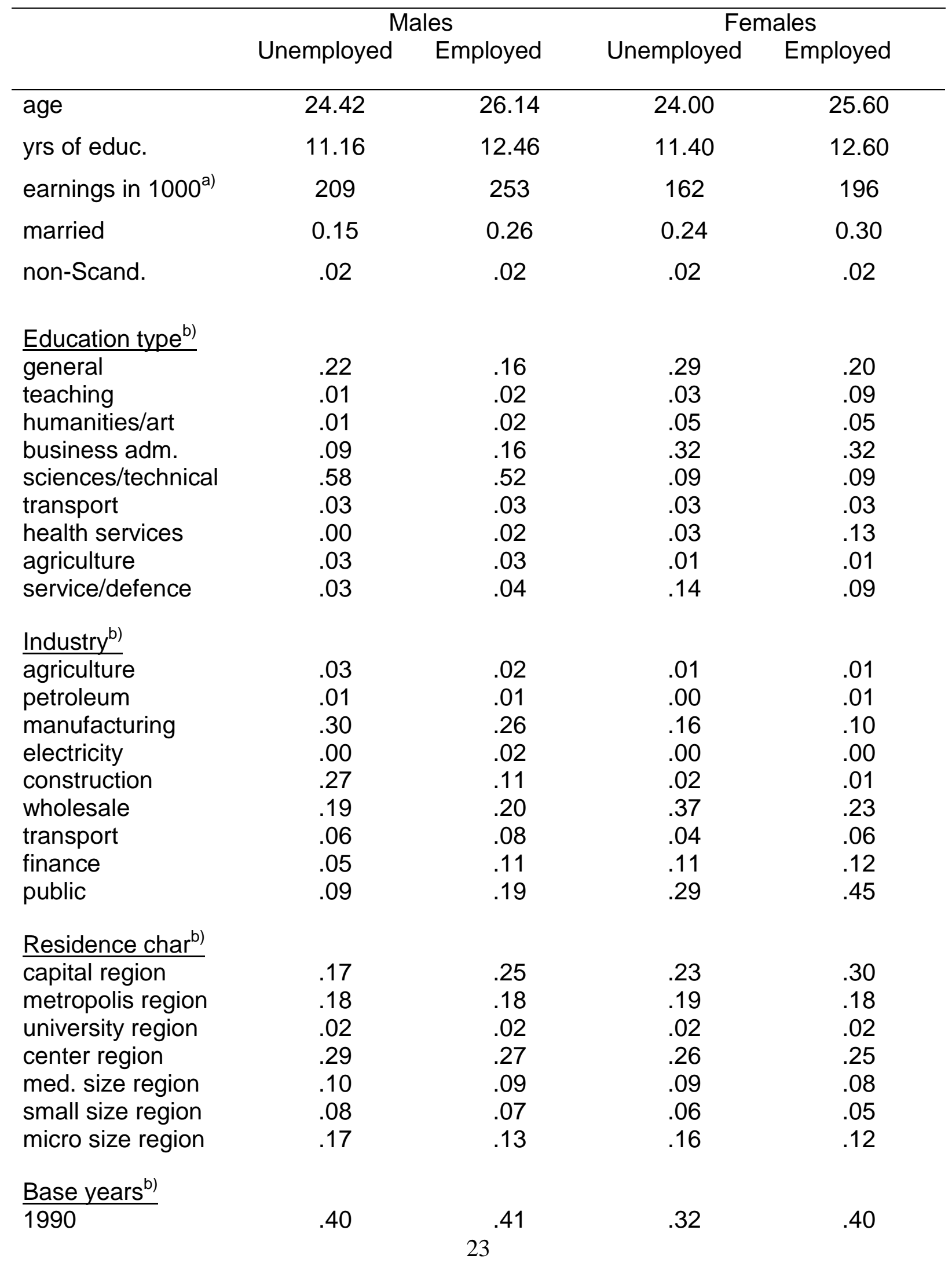




\begin{tabular}{lllll}
1991 & .11 & .07 & .11 & .09 \\
1992 & .11 & .08 & .11 & .09 \\
1993 & .09 & .06 & .09 & .08 \\
1994 & .07 & .06 & .09 & .07 \\
1995 & .06 & .06 & .08 & .07 \\
1996 & .06 & .07 & .08 & .07 \\
1997 & .05 & .09 & .06 & .07 \\
1998 & .05 & .09 & .06 & .07 \\
Unempl.rates (base & 6.28 & 5.69 & 4.55 & 4.28 \\
year) & & & & \\
\hline
\end{tabular}
a) Fixed NOK 2000 prices.
b) Shares in each category within each group; unemployed and employed.
Summarizes vertically to 1 


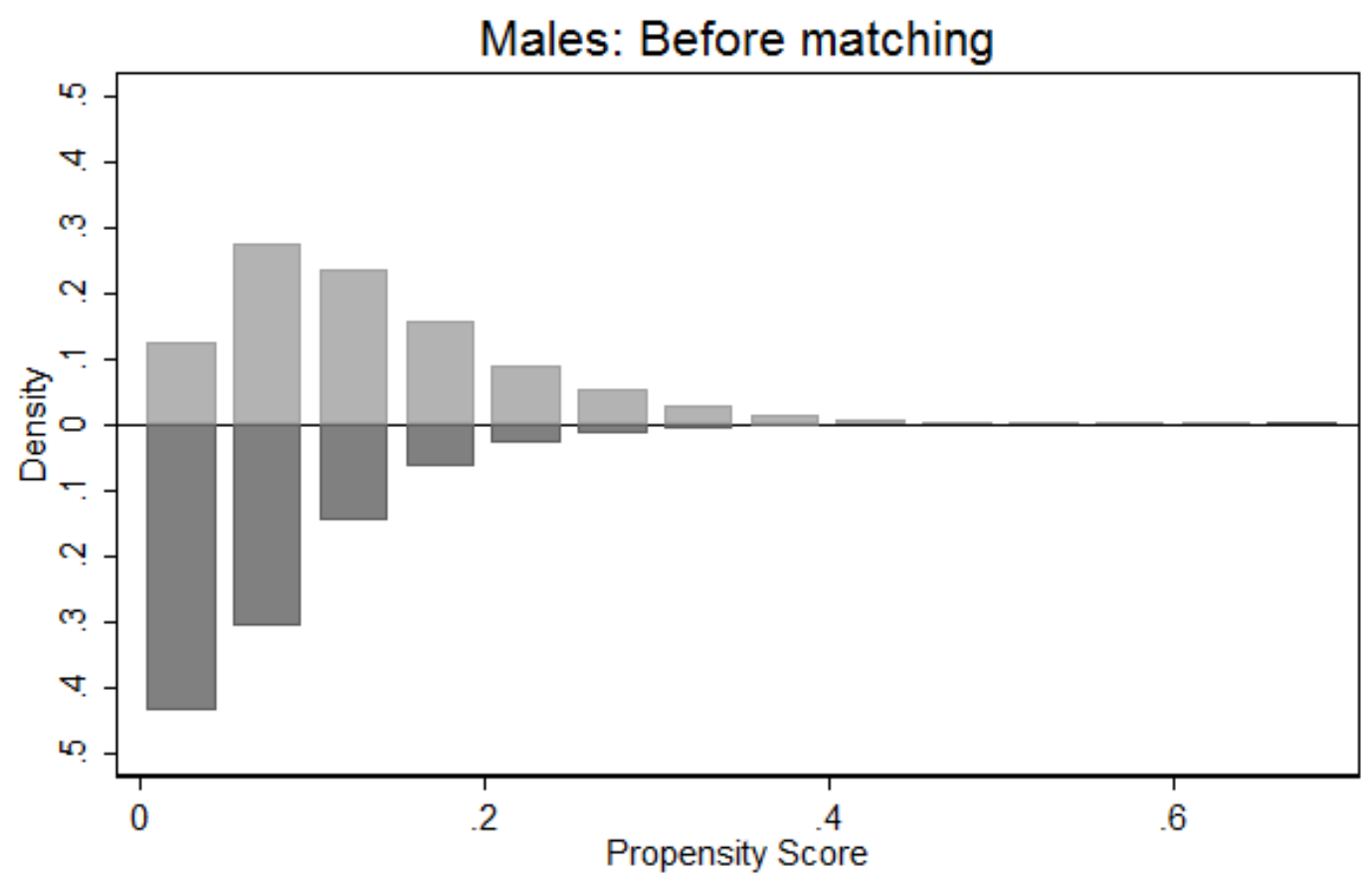

\begin{tabular}{|l|l|}
\hline Control (Employed) & Treated (Unemployed) \\
\hline
\end{tabular}

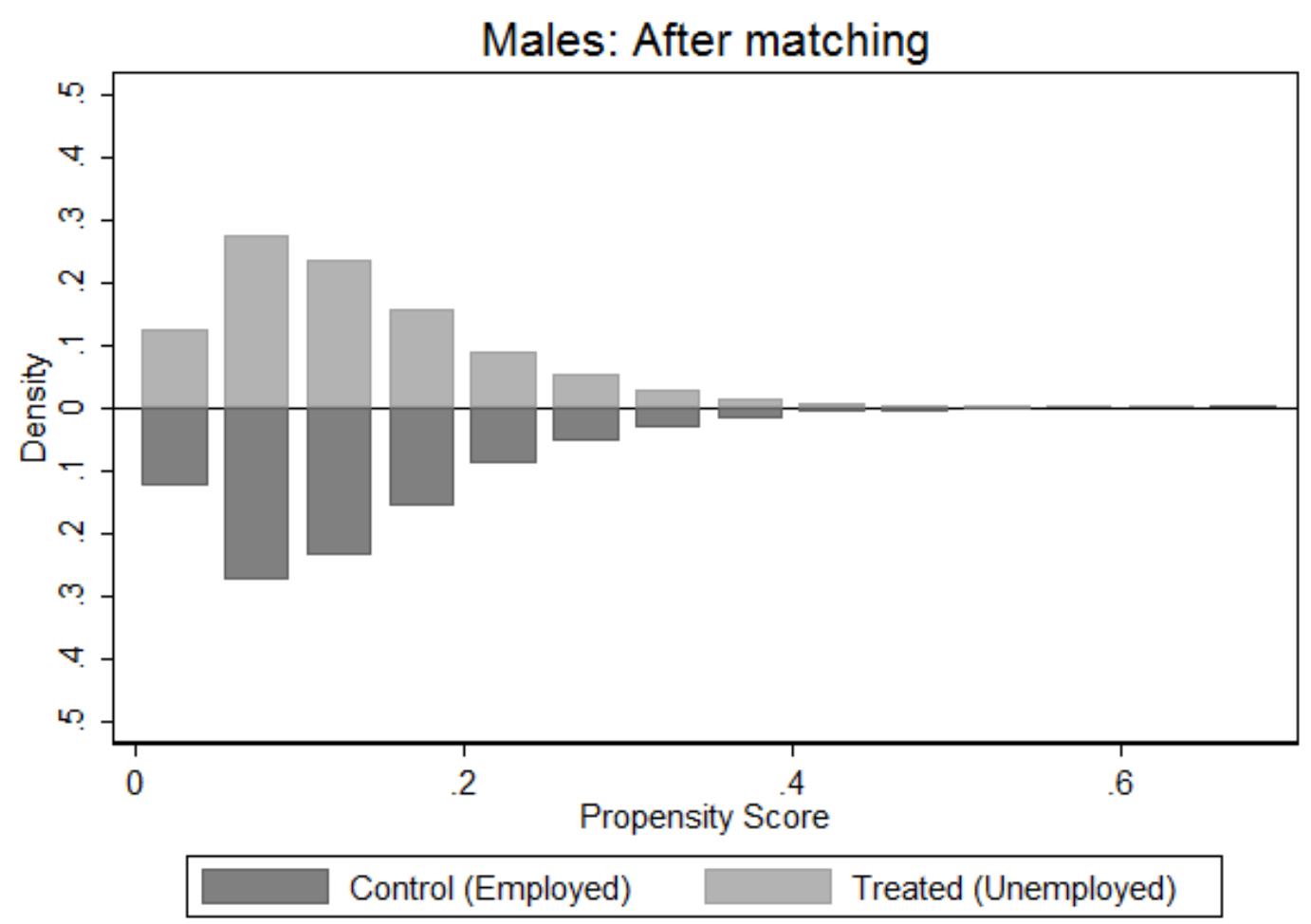

Figure 1: Propensity scores before and after matching -males.

Note: The Control (Employed) group consist of all individuals in the employed group before matching and a limited sample of the employed after matching. 
Females: Before matching

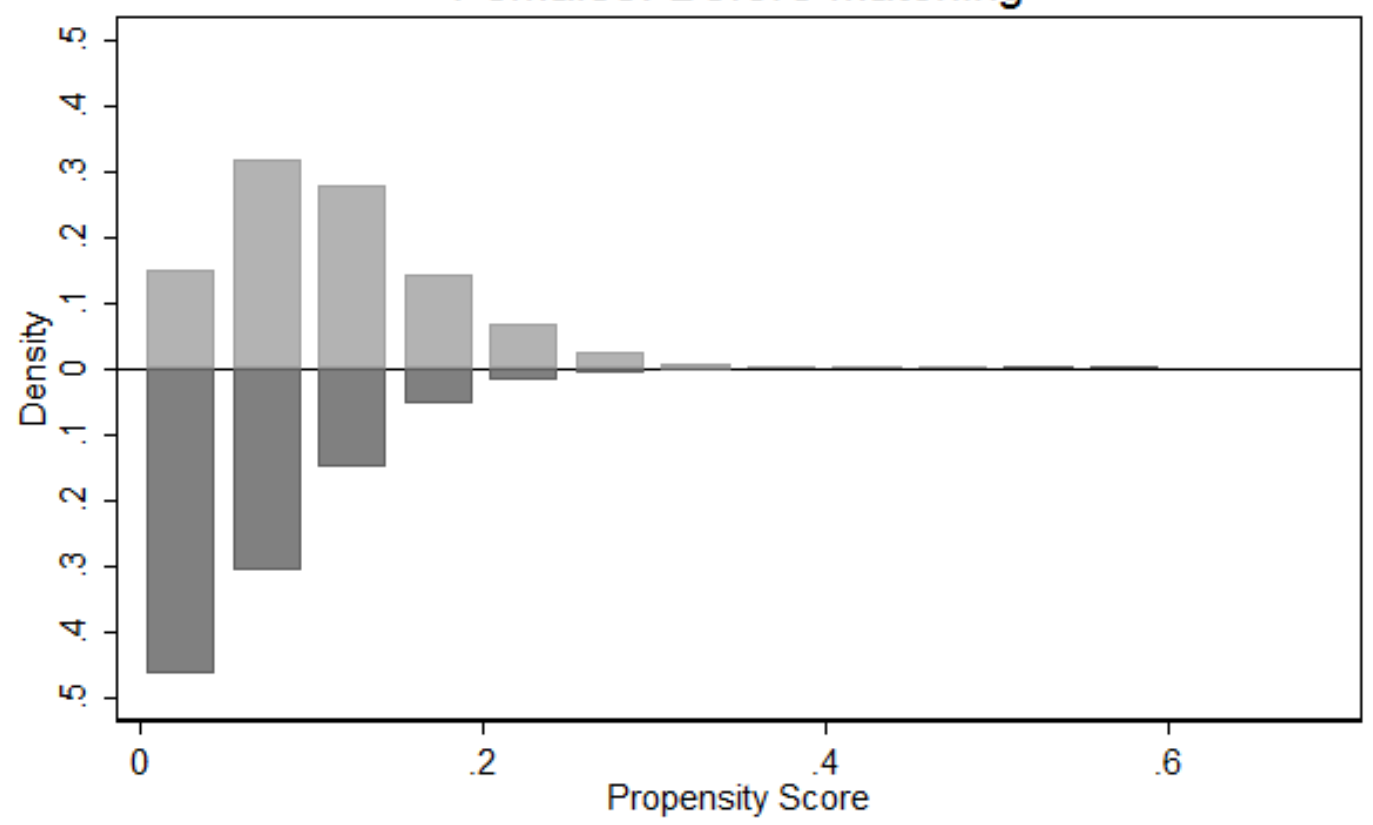

\begin{tabular}{|l|l|l|}
\hline Control (Employed) & Treated (Unemployed)
\end{tabular}

Females: After matching

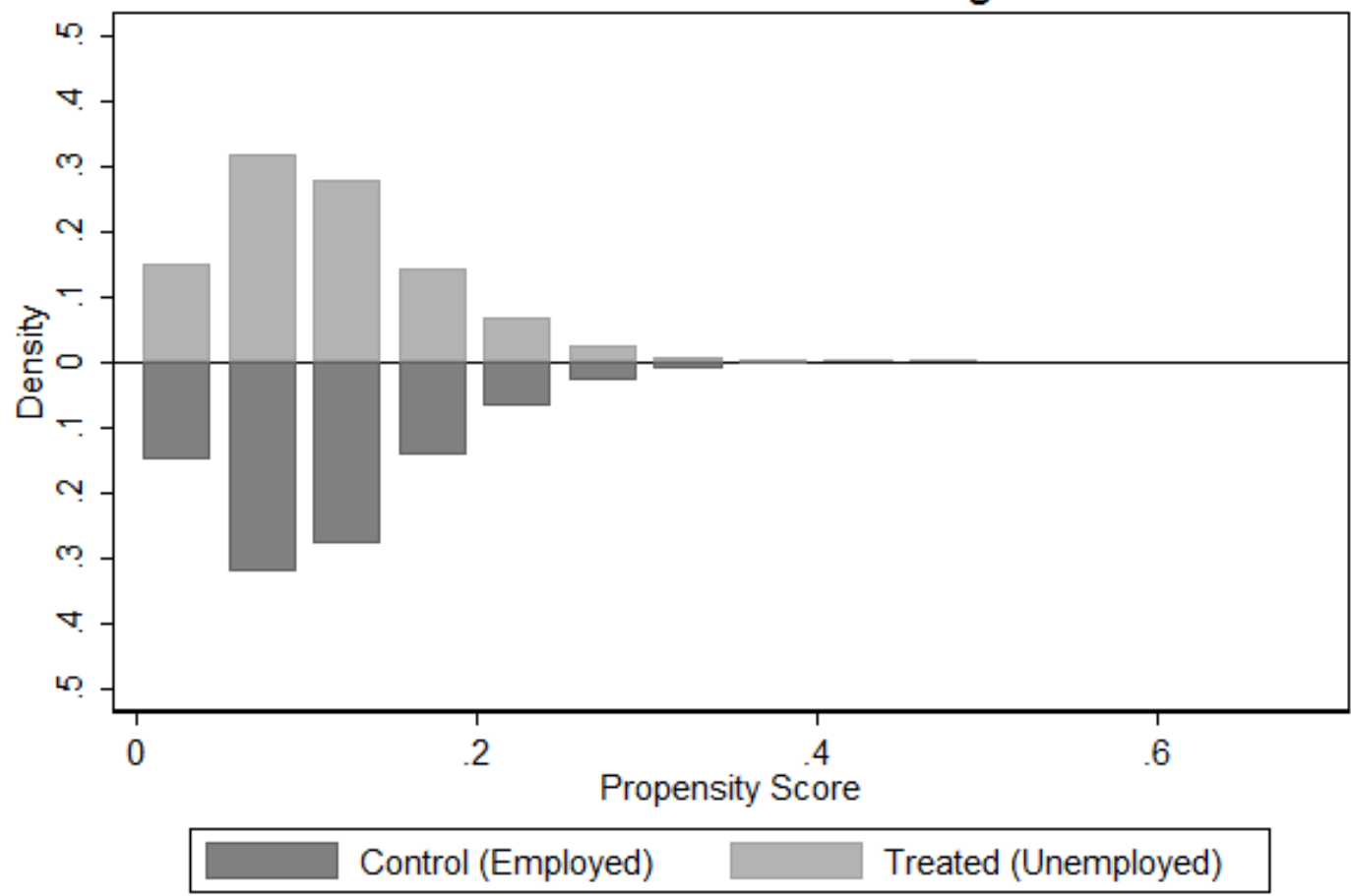

Figure 2: Propensity scores before and after matching -females.

Note: The Control (Employed) group consist of all individuals in the employed group before matching and a limited sample of the employed after matching. 
Table 2: Descriptive statistics after matching

Mean values and shares. All characteristics measured the year prior to a base year.

\begin{tabular}{|c|c|c|c|c|c|c|c|c|}
\hline & \multicolumn{4}{|c|}{ Males } & \multicolumn{4}{|c|}{ Females } \\
\hline & $\begin{array}{l}\text { Treated } \\
\text { (Unempl } \\
\text { oyed) }\end{array}$ & Control & $\begin{array}{l}\text { |bias| } \\
(\%)^{a)}\end{array}$ & $p$-value & $\begin{array}{l}\text { Treated } \\
\text { (Unem } \\
\text { ployed) }\end{array}$ & Control & $\begin{array}{l}\mid \text { bias } \\
(\%)^{a}\end{array}$ & $p$-value \\
\hline age & 24.42 & 24.40 & 0.8 & 0.41 & 24.00 & 24.02 & 1.0 & 0.39 \\
\hline yrs. of educ. & 11.16 & 11.14 & 0.7 & 0.38 & 11.40 & 11.40 & 0.2 & 0.84 \\
\hline $\begin{array}{l}\text { earnings in } \\
1000^{\text {b) }}\end{array}$ & 209 & 209 & 0.1 & 0.88 & 162 & 162 & 0.1 & 0.95 \\
\hline married & .15 & .15 & 0.6 & 0.52 & .24 & .24 & 0.7 & 0.60 \\
\hline non-Scand. & .02 & .02 & 0.4 & 0.70 & .02 & .02 & 0.7 & 0.56 \\
\hline \multicolumn{9}{|l|}{ Education type $^{\text {c) }}$} \\
\hline $\begin{array}{l}\text { general } \\
\text { teaching } \\
\text { humanities/art } \\
\text { business adm. } \\
\text { sciences/ techn. } \\
\text { transport } \\
\text { health services } \\
\text { agriculture } \\
\text { service/defence }\end{array}$ & $\begin{array}{l}.22 \\
.01 \\
.01 \\
.09 \\
.58 \\
.03 \\
.00 \\
.03 \\
.03\end{array}$ & $\begin{array}{l}.22 \\
.00 \\
.01 \\
.09 \\
.58 \\
.03 \\
.00 \\
.03 \\
.03\end{array}$ & $\begin{array}{l}0.4 \\
0.4 \\
1.2 \\
0.8 \\
0.1 \\
0.5 \\
0.4 \\
0.0 \\
0.3\end{array}$ & $\begin{array}{l}0.72 \\
0.57 \\
0.19 \\
0.38 \\
0.90 \\
0.68 \\
0.30 \\
1.00 \\
0.90\end{array}$ & $\begin{array}{l}.29 \\
.03 \\
.05 \\
.32 \\
.09 \\
.03 \\
.03 \\
.01 \\
.14\end{array}$ & $\begin{array}{l}.28 \\
.03 \\
.05 \\
.33 \\
.09 \\
.03 \\
.03 \\
.01 \\
.14\end{array}$ & $\begin{array}{l}0.7 \\
0.5 \\
0.1 \\
1.3 \\
1.1 \\
0.3 \\
1.6 \\
0.4 \\
0.9\end{array}$ & $\begin{array}{l}0.61 \\
0.64 \\
0.93 \\
0.30 \\
0.41 \\
0.80 \\
0.05 \\
0.75 \\
0.51\end{array}$ \\
\hline \multicolumn{9}{|l|}{ Industryc) } \\
\hline agriculture & .03 & .03 & 1.1 & 0.33 & .01 & .01 & 0.4 & 0.76 \\
\hline petroleum & .01 & .01 & 0.2 & 0.82 & .00 & .00 & 0.0 & 1.00 \\
\hline manufacturing & .30 & .30 & 0.3 & 0.78 & .16 & .16 & 0.9 & 0.52 \\
\hline electricity & .00 & .00 & 0.7 & 0.31 & .00 & .00 & 0.8 & 0.35 \\
\hline construction & .27 & .27 & 0.9 & 0.50 & .02 & .02 & 0.8 & 0.57 \\
\hline wholesale & .19 & .19 & 0.9 & 0.40 & .37 & .37 & 0.5 & 0.70 \\
\hline transport & .06 & .06 & 0.2 & 0.87 & .04 & .04 & 0.9 & 0.43 \\
\hline finance & .05 & .05 & 0.1 & 0.90 & .11 & .11 & 0.7 & 0.55 \\
\hline public & .09 & .10 & 0.5 & 0.62 & .29 & .29 & 0.5 & 0.66 \\
\hline
\end{tabular}

Residence

char. ${ }^{\text {c) }}$

$\begin{array}{lllllllll}\text { capital region } & .17 & .17 & 0.2 & 0.86 & .23 & .22 & 0.9 & 0.45 \\ \begin{array}{l}\text { metropolis } \\ \text { region }\end{array} & .18 & .18 & 1.1 & 0.32 & .19 & .18 & 1.4 & 0.28 \\ \text { university } & .02 & .02 & 0.5 & 0.64 & .02 & .02 & 0.6 & 0.63\end{array}$

region 


\begin{tabular}{|c|c|c|c|c|c|c|c|c|}
\hline center region & .29 & .28 & 0.9 & 0.43 & .26 & .27 & 2.1 & 0.11 \\
\hline $\begin{array}{l}\text { med. size } \\
\text { region }\end{array}$ & .10 & .10 & 0.3 & 0.79 & .09 & .09 & 0.4 & 0.75 \\
\hline $\begin{array}{l}\text { small size } \\
\text { region }\end{array}$ & .08 & .08 & 0.6 & 0.60 & .06 & .06 & 0.5 & 0.69 \\
\hline $\begin{array}{l}\text { micro size } \\
\text { region }\end{array}$ & .17 & .17 & 0.1 & 0.92 & .16 & .16 & 0.2 & 0.90 \\
\hline \multicolumn{9}{|l|}{ Base years $^{c)}$} \\
\hline$\overline{1990}$ & .40 & .40 & 1.1 & 0.31 & .32 & 32. & 0.4 & 0.73 \\
\hline 1991 & .11 & .11 & 0.1 & 0.92 & .11 & .11 & 0.1 & 0.92 \\
\hline 1992 & .11 & .11 & 1.3 & 0.27 & .11 & .11 & 0.1 & 0.94 \\
\hline 1993 & .09 & .09 & 0.5 & 0.69 & .09 & .09 & 0.5 & 0.71 \\
\hline 1994 & .07 & .07 & 1.9 & 0.08 & .09 & .09 & 1.7 & 0.22 \\
\hline 1995 & .06 & .06 & 0.2 & 0.82 & .08 & .08 & 0.7 & 0.60 \\
\hline 1996 & .06 & .06 & 0.4 & 0.74 & .08 & .08 & 0.2 & 0.91 \\
\hline 1997 & .05 & .05 & 0.3 & 0.77 & .06 & .06 & 1.3 & 0.29 \\
\hline 1998 & .05 & .05 & 0.2 & 0.79 & .06 & .06 & 1.3 & 0.27 \\
\hline$\frac{\text { Unempl. rates }}{\text { (base year) }}$ & 6.28 & 6.27 & 0.4 & 0.74 & 4.55 & 4.57 & 1.2 & 0.34 \\
\hline $\begin{array}{l}\text { Nbr of } \\
\text { individuals }\end{array}$ & 17169 & 17169 & & & 12187 & 12187 & & \\
\hline
\end{tabular}

a) Absolute standardised bias.

b) Fixed NOK 2000 prices.

c) Shares in each category within each group; unemployed and employed.

Summarizes vertically to 1 . 


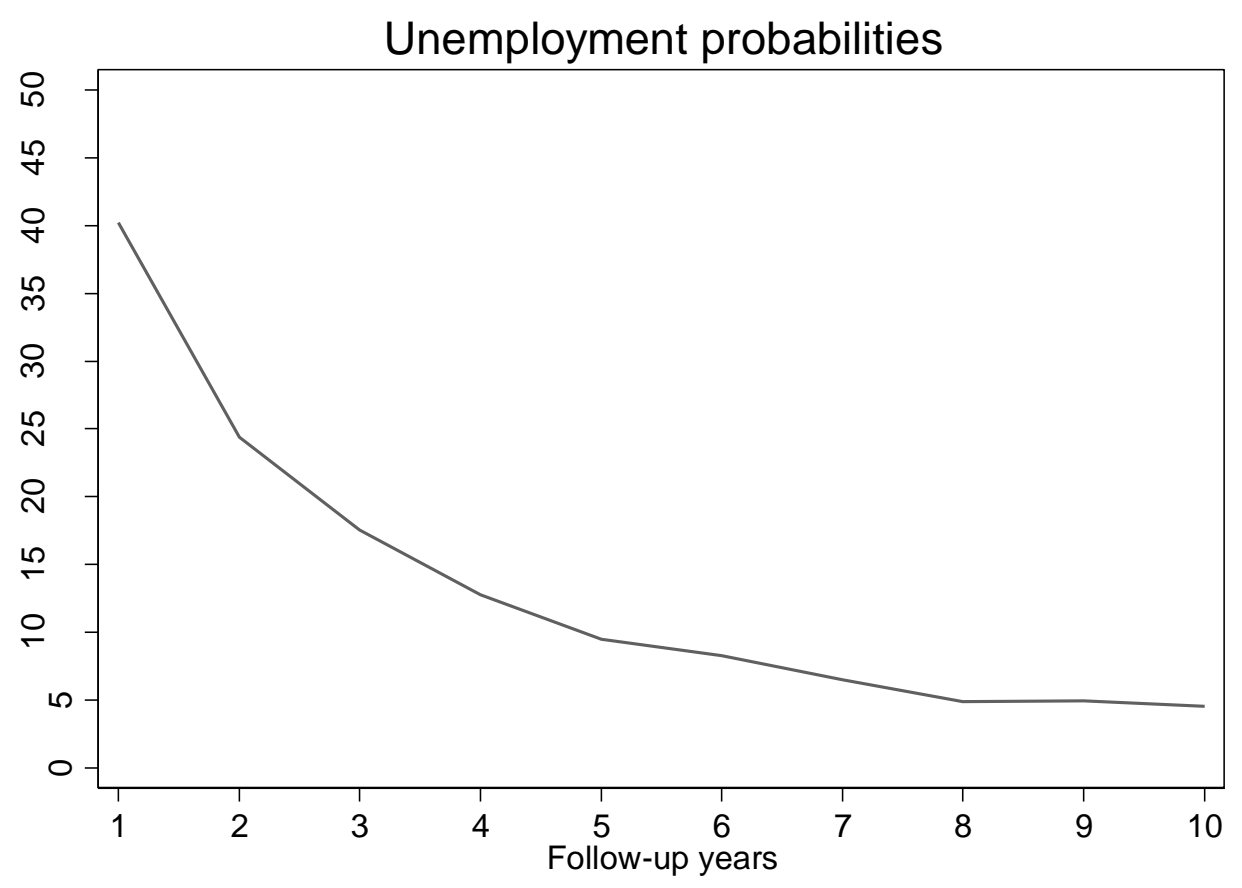

Figure 3: Average treatment effect on the treated (ATT) on the probability of being unemployed in the follow-up years -males.

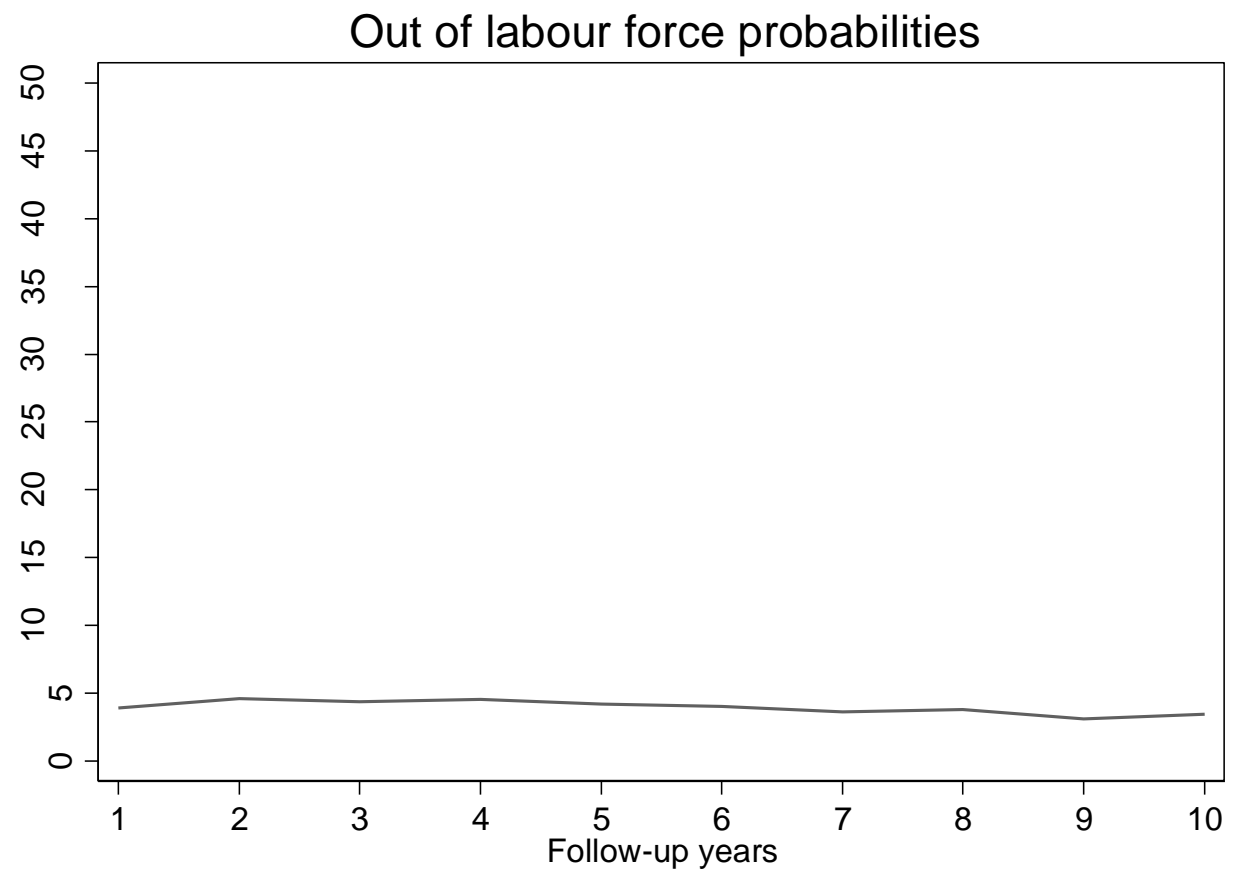

Figure 4: Average treatment effect on the treated (ATT) on the probability of being out of labour force in the follow-up years -males. 


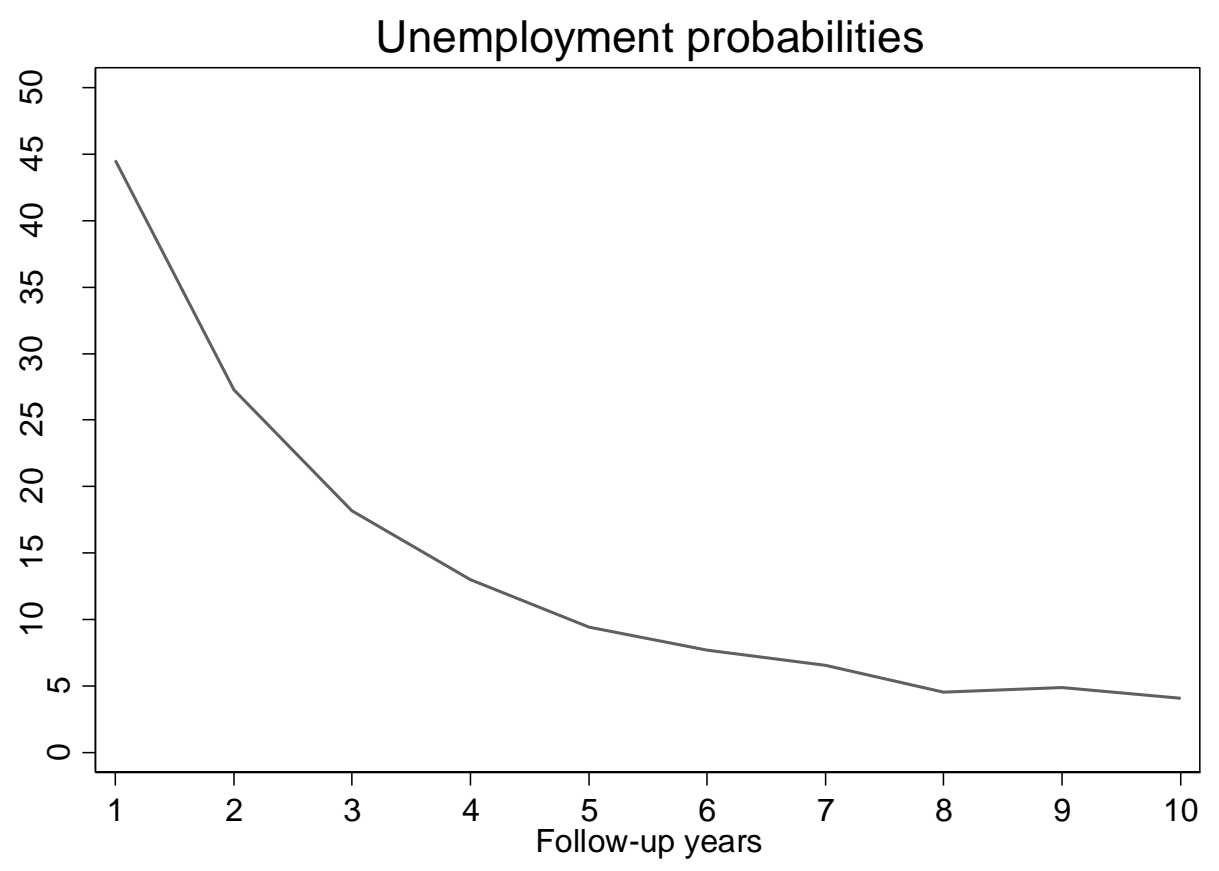

Figure 5: Average treatment effect on the treated (ATT) on the probability of being unemployed in the follow-up years -females.

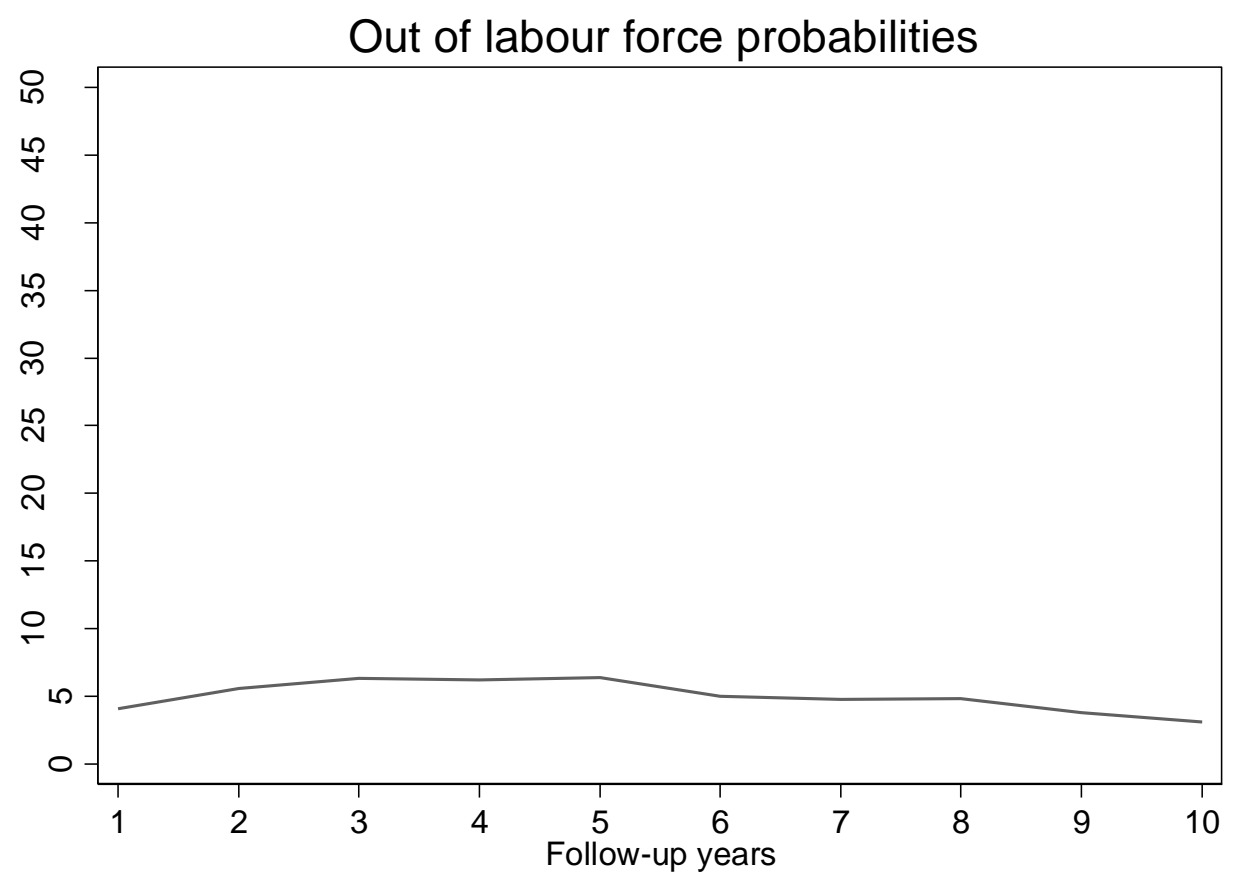

Figure 6: Average treatment effect on the treated (ATT) on the probability of being out of labour force in the follow-up years -females. 
Table 3: Robustness check, MH-test

Follow-up years

$m h+m h-m h+m h-m h+m h-m h+m h-m h+m h-m h+m h-m h+m h-m h+m h-m h+m h-m h+m h-$

Males

Unemployment

$e^{\mathrm{V}}=1.0$

$e^{\gamma}=1.5$

$e^{v}=2.0$

Out of labour

force

$e^{V}=1.0$

$e^{y}=1.5$

$e^{y}=2.0$

$$
\begin{array}{rrrrrrrrrrrrrrrrrrrr}
0 & 0 & 0 & 0 & 0 & 0 & 0 & 0 & 0 & 0 & 0 & 0 & 0 & 0 & 0 & 0 & 0 & 0 & 0 & 0 \\
0 & 0 & 0 & 0 & 0.02 & 0 & 0.07 & 0 & 0.46 & 0 & 0.08 & 0 & 0 & 0 & 0.01 & 0 & - & 0 & - & 0 \\
0.45 & 0 & 0.01 & 0 & - & 0 & - & 0 & - & 0 & - & 0 & - & 0 & - & 0 & - & 0 & - & 0
\end{array}
$$

\section{Females}

\section{Unemployment}

$e^{\gamma}=1.0$

$e^{\gamma}=1.5$

$e^{\gamma}=2.0$

\section{Out of labour}

\section{force}

$e^{v}=1.0$

$e^{y}=1.5$

$e^{V}=2.0$

$$
\begin{array}{rrrrrrrrrrrrrrrrrrrr}
0 & 0 & 0 & 0 & 0 & 0 & 0 & 0 & 0 & 0 & 0 & 0 & 0 & 0 & 0 & 0 & 0 & 0 & 0 & 0 \\
0 & 0 & 0 & 0 & 0 & 0 & 0 & 0 & 0 & 0 & 0 & 0 & 0 & 0 & 0.01 & 0 & 0 & 0 & 0.01 & 0 \\
0 & 0 & 0 & 0 & 0 & 0 & 0 & 0 & 0.01 & 0 & 0.38 & 0 & 0.28 & 0 & - & 0 & - & 0 & - & 0
\end{array}
$$

Notes:

\begin{tabular}{rrrrrrrrrrrrrrrrrrrr}
0 & 0 & 0 & 0 & 0 & 0 & 0 & 0 & 0 & 0 & 0 & 0 & 0 & 0 & 0 & 0 & 0 & 0 & 0 & 0 \\
0.10 & 0 & 0.12 & 0 & 0.21 & 0 & 0.45 & 0 & 0.33 & 0 & - & 0 & - & 0 & - & 0 & - & 0 & - & 0 \\
- & 0 & - & 0 & - & 0 & - & 0 & - & 0 & - & 0 & - & 0 & - & 0 & - & 0 & - & 0 \\
\hline
\end{tabular}

The $m h+$ denotes $p$-values of the upper bound, while the $m h$-denotes the $p$-values of the lower bound.

A "-" denotes a negative treatment effect resulting from assuming a large positive unobserved heterogeneity bias. 


\section{Appendix}
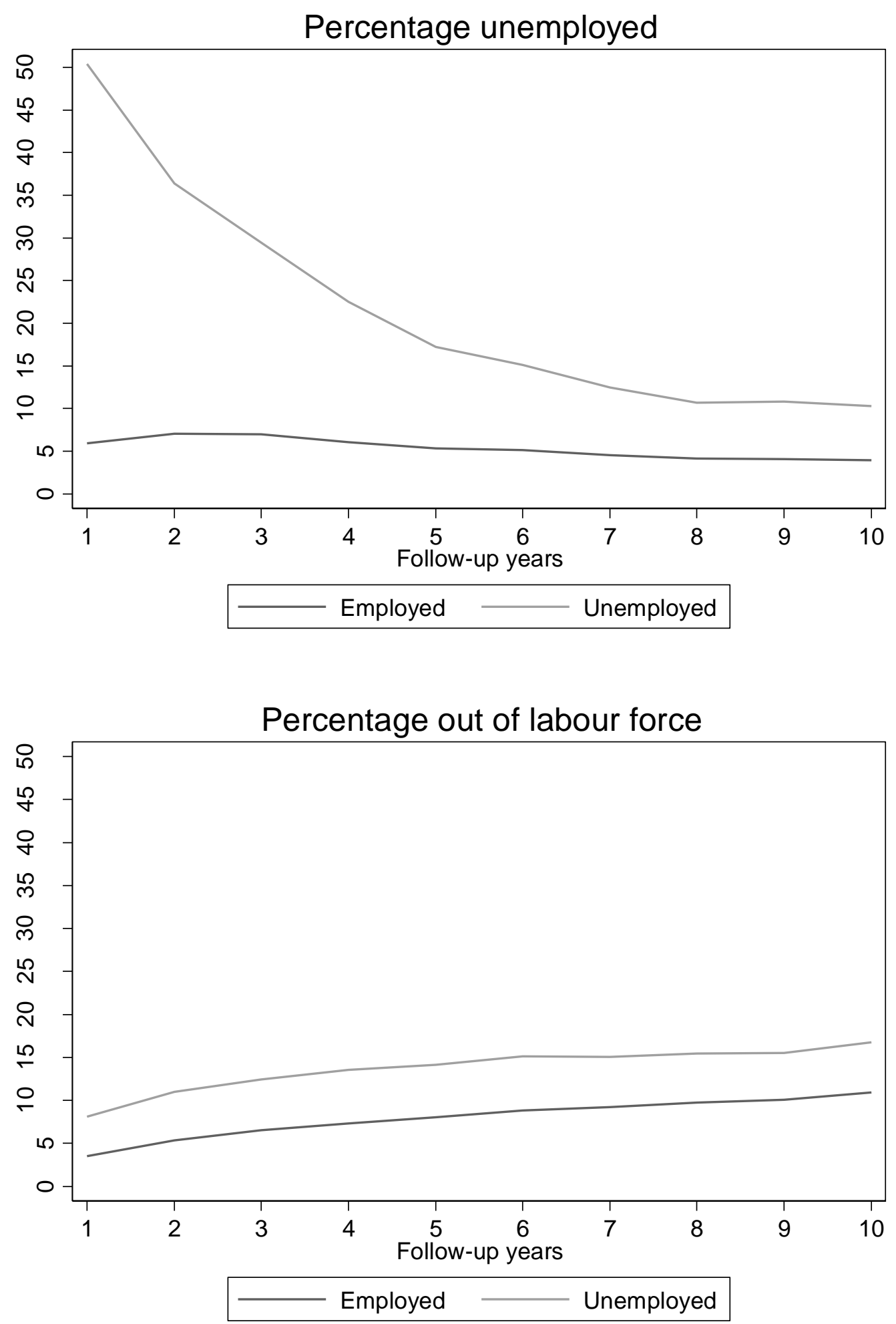

Figure A1: Shares of males in the two groups (employed and unemployed) being unemployed and out of labour force in the follow-up years. 

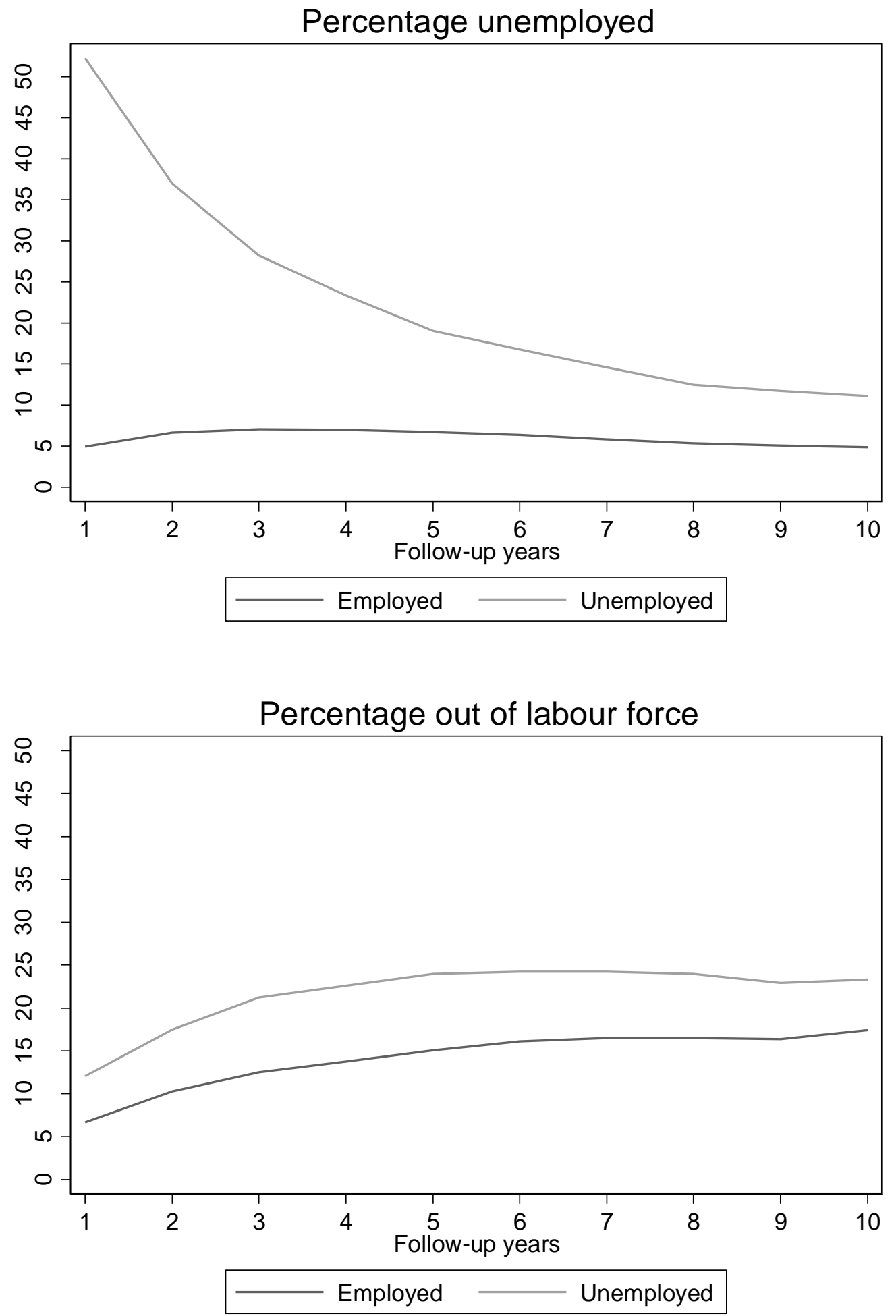

Figure A2: Shares of females in the two groups (employed and unemployed) being unemployed and out of labour force in the follow-up years. 